\title{
Ethanolic Extract of Leaves of Newbouldia laevis Attenuates Glycosylation of Hemoglobin and Lipid Peroxidation in Diabetic Rats
}

\author{
${ }^{1}$ Kolawole O. Timothy, ${ }^{2}$ Akanji M. Adewumi, ${ }^{1}$ Awe O. Emmanuel and ${ }^{3}$ Akiibinu M. Olayemi \\ ${ }^{1}$ Department of Pharmacology and Therapeutics, Ladoke Akintola University of Technology, Ogbomoso, Nigeria \\ ${ }^{2}$ Department of Biochemistry, University of Ilorin, Ilorin, Nigeria \\ ${ }^{3}$ Department of Chemistry and Biochemistry, Caleb University, Lagos, Nigeria
}

Received 2013-05-28, Revised 2013-08-04; Accepted 2013-11-13

\begin{abstract}
Diabetes is one of the major health problems around the world and the incidence of this metabolic disorder is on the increase. Current therapeutic interventions have not done much in preventing complications of diabetes. Therefore this study investigated the effect of ethanolic extract of Newbouldia laevis leaves (NLet) on lipid peroxidation and glycosylation of hemoglobin, which are pathological indicators of diabetes mellitus. Diabetes was induced in Wistar rats by intravenous injection of streptozotocin $\left(60 \mathrm{mg} \mathrm{kg}^{-1}\right)$. Diabetic rats were then treated orally with NLet for 28 days. After the treatment, the concentration of Malondialdehyde (MDA) in the liver, kidney and pancreas of the rats was estimated. Fasting blood glucose was determined and oral glucose tolerance test was also carried out. Other groups of STZ-diabetic rats were treated for 8 weeks and percentage glycosylated hemoglobin $(\mathrm{HbA} 1 \mathrm{c})$ was measured. Fasting blood glucose of treated diabetic rats significantly $(\mathrm{p}<0.05)$ decreased in a dose-dependent manner when compared with untreated diabetic control rats. After oral glucose load, blood glucose level reached a peak at $60 \mathrm{~min}$. In both non-diabetic and diabetic rats, treatment with the extract significantly $(p<0.01)$ reduced the blood glucose level at 120 and $180 \mathrm{~min}$. The percentage total hemoglobin glycated in diabetic rats significantly reduced $(\mathrm{p}<0.05)$ after the 8 -week treatment with NLet. MDA concentration in the liver, kidney and pancreas of diabetic rats was also dose-dependently reduced by the extract. At 300 and $500 \mathrm{mg} \mathrm{kg}^{-1}$, the reduction was significant $(\mathrm{p}<0.05)$ compared with the diabetic control. The effects of NLet were comparable to those observed with glibenclamide. The results of this study suggest that NLet can prevent the complications of diabetes that result from glycation of hemoglobin and lipid peroxidation.
\end{abstract}

Keywords: Diabetes, Newbouldia Laevis, Glycosylation, Lipid Peroxidation, Glucose

\section{INTRODUCTION}

Diabetes mellitus is a metabolic disorder with heterogeneous etiologies. It is characterized by chronic hyperglycemia and disturbances of carbohydrate, fat and protein metabolism resulting from defects in insulin secretion, insulin action, or both (Alberti and Zimmet, 1998). It develops when the pancreas does not produce enough insulin or when the body cannot effectively utilize the insulin it produces. In diabetes, glycosylation of hemoglobin and lipid peroxidation are important processes in the development and progression of complications of diabetes (Latha and Pari, 2004). Glycosylation is a spontaneous non-enzymatic reaction in which glucose binds covalently with hemoglobin to produce glycosylated (or glycated) hemoglobin (HbA1c). Enzymatic glycosylation of hemoglobin continues unabated in the presence of chronic hyperglycemia. This Technology, Ogbomoso, Nigeria Tel: +234 8039328444 
ultimately leads to the accumulation of Advanced Glycation Endproducts (AGEs). The AGEs react with Receptors for Advanced Glycation Endproducts (RAGE) to promote the process that leads to endothelial dysfunction and then cardiovascular complications of diabetes (Yan et al., 2007). Glycosylated hemoglobin provides information about long-term blood glucose control because once a hemoglobin molecule is glycated, it remains in the red blood cell for the rest of its lifespan, which is about 120 days (Syed, 2011). Compared to Fasting Blood Glucose (FBG) and Oral Glucose Tolerance Test (OGTT), HbAlc is a better diagnostic parameter for diabetic complications. Therefore in 2009 , HbAlc was recommended as a diagnostic test for diabetes mellitus with a threshold $>6.5 \%$ (IEC, 2009).

During glycation and glucose and lipid oxidation, Reactive Oxygen Species (ROS) are generated. This results in an imbalance between free radical and antioxidant levels, which triggers oxidative stress in the cells. Lipid peroxidation is an important biomarker of oxidative stress and contributes to the development of atherosclerosis in diabetes mellitus (Giugliano et al., 1996). Both glycosylation of hemoglobin and lipid peroxidation are therefore important pathological indicators in diabetes mellitus.

Globally, the socio-economic impact of diabetes is enormous. This is especially the case in countries with limited resources. To successfully cope with this challenging situation, there is an urgent need to search for more treatment options that are readily available, safe and cost-effective. Medicinal plants have proved useful in the treatment of diabetes. They provide considerable economic benefit to rural and poor people who may not be able to afford the expensive synthetic drugs. They are also sources of lead molecules for the synthesis of new anti-diabetic drugs. For these reasons, World Health Organization (WHO) recommended and encouraged the use of herbal medicine especially in countries where access to the conventional treatment of diabetes is not adequate (Elujoba et al., 2005).

Newbouldia laevis (P. Beauv) is a medicinal plant that is employed in the management of diabetes across African countries. It is a medium sized angiosperm which belongs to the Bignoniaceae family. Its common names are 'African Border Tree' and 'Fertility Tree'. In Nigeria, it is known as 'Aduruku' in Hausa, 'Ogirisi' in Igbo and 'Akoko' in Yoruba languages. It is used by African traditional healers to treat various ailments. In Nigeria, a decoction of the bark is given to children to treat epilepsy and convulsions. The leaves are soaked in ethanol for the treatment of diabetes and sickle cell. Different parts of the plant have been reported to possess antimicrobial properties (Kuete et al., 2007; Ogunlana and Ogunlana, 2008). The leaf extract of the plant was also reported to lower blood glucose level in diabetic rats (Owolabi et al., 2011). However, the effects of the plant on glycosylation of hemoglobin and lipid peroxidation have not been studied. In this study, we investigated the effects of ethanolic extract of the leaves of Newbouldia laevis on glycosylation of hemoglobin and lipid peroxidation in diabetic rats.

\section{MATERIALS AND METHODS}

\subsection{Collection of Plant Material}

Leaves of Newbouldia laevis were collected from the premises of College of Health Sciences, Ladoke Akintola University of Technology, Mercyland, Osogbo Campus, Nigeria. The plant sample was identified and authenticated by a taxonomist in Forestry Research Institute of Nigeria (FRIN), Ibadan, Nigeria. A voucher specimen was deposited in the herbarium of the institute (voucher specimen no: FHI 107753).

\subsection{Preparation of Newbouldia Laevis Extract}

The leaves were thoroughly washed with distilled water to remove soil and other debris that may contaminate the plant sample. The washed sample was then air-dried under shade in the laboratory for 5 days and the dry plant sample was pulverized using an electric grinding machine. The resultant powder sample weighing $500 \mathrm{~g}$ was then extracted with $80 \%$ ethanol at $70^{\circ} \mathrm{C}$ by continuous hot percolation using a Soxhlet apparatus. The extraction was carried out for $24 \mathrm{~h}$ and the resulting ethanolic extract was concentrated at $40^{\circ} \mathrm{C}$ in a rotary evaporator. The solid sample obtained weighed $47.5 \mathrm{~g}$ (yield $=9.5 \%$ ). The crude ethanolic extract (NLet) was kept in air-tight container and stored in a refrigerator at $4{ }^{\circ} \mathrm{C}$ until the time of use.

\subsection{Experimental Animals}

Wistar rats of both sexes weighing 180-200 g were obtained from the Animal Holding Unit of the Department of Biochemistry, University of Ilorin, Ilorin, Nigeria. All experimental procedures were conducted in accordance with National Institute of Health Guide for the Care and Use of Laboratory Animals (NIH, 1985) as well as Ethical Guidelines for the Use of Laboratory Animals in LAUTECH, Ogbomoso, Nigeria. The animals were housed in polypropylene cages inside a 
well-ventilated room. A maximum of six animals were kept in one cage. The animals were maintained under standard laboratory conditions of temperature $\left(22 \pm 2^{\circ} \mathrm{C}\right)$, relative humidity $(55-65 \%)$ and $12 \mathrm{~h}$ light/dark cycle. During the whole experimental period, animals were fed with a standard balanced commercial pellet diet Ladokun Feeds Ltd. Ibadan, Nigeria.

\subsection{Induction of Diabetes in Rats}

Experimental diabetes was induced in rats which had fasted for $12 \mathrm{~h}$ by a single intravenous injection through the tail vein of a freshly prepared solution of Streptozotocin (STZ) $\left(60 \mathrm{mg} \mathrm{kg}^{-1}\right.$ b.wt) dissolved in $0.1 \mathrm{M}$ cold citrate buffer, pH 4.5 (Chen et al., 2005). The rats were allowed to drink 5\% glucose solution overnight to overcome drug-induced hypoglycemia. Estimation of Fasting Blood Glucose (FBG) was done 72 hours after injection of STZ to confirm induction of diabetes and then on the 7 th day to investigate the stability of diabetic condition. Fasting blood glucose was estimated by One Touch ${ }^{\circledR}$ glucometer (Lifescan, Inc. 1995 Milpas, California, USA). Blood sample for the FBG determination was obtained from the tail vein of the rats and those with blood glucose value $\geq 200$ $\mathrm{mg} \mathrm{dl}^{-1}$ were selected for the study.

\subsection{Experimental Design}

Rats were divided into a group of non-diabetic rats and five groups of STZ-diabetic rats. Each of the six groups consists of 6 rats. Group I = non-diabetic rats (control); Group II = STZ-diabetic rats; Group III = diabetic rats treated with NLet $\left(150 \mathrm{mg} \mathrm{kg}^{-1}\right)$; Group IV $=$ diabetic rats treated with NLet $\left(300 \mathrm{mg} \mathrm{kg}^{-1}\right)$; Group V $=$ diabetic rats treated with NLet $\left(500 \mathrm{mg} \mathrm{kg}^{-1}\right)$; Group $\mathrm{VI}=$ glibenclamide $\left(5 \mathrm{mg} \mathrm{kg} \mathrm{kg}^{-1}\right)$. The fasting blood glucose was measured on day 0 at $8.00 \mathrm{am}$. All the drugs were administered orally twice a day at 8.00 am and 8.00 pm for 28 days using a sterile syringe fitted with a sterile cannula. Rats in groups I and II were treated orally with distilled water for the four weeks. Blood glucose was measured on the 15th and 29th day after the animals have fasted for $12 \mathrm{~h}$.

\subsection{Estimation of Fasting Blood Glucose}

All animals were fasted overnight and blood was collected from the tail vein on Day 0 and Day 15. On Day 29, the rats were euthanized under chloroform vapor. The jugular vein was exposed and cut with a sterile scalpel blade and the rats were bled into specimen bottles. Blood samples were transferred to sterilized centrifuge tubes and allowed to clot at room temperature. The blood samples were centrifuged for $10 \mathrm{~min}$ at $1500 \mathrm{rpm}$. The serum obtained was used for blood glucose analysis. Blood glucose was estimated using glucose assay kit (Randox Laboratory Ltd. UK). This is based on Glucose Oxidase/Peroxidase (GOD/POD) method (Trinder, 1969).

\subsection{Oral glucose Tolerance Test (OGTT) in Normal and Diabetic Rats}

Prior to OGTT, all the rats were fasted for $12 \mathrm{~h}$. Distilled water (control), a reference drug glibenclamide $\left(5 \mathrm{mg} \mathrm{kg}^{-1}\right.$ b.wt.) or each of the three different doses of the ethanolic extract $\left(500 \mathrm{mg} \mathrm{kg}^{-1}\right.$ b.wt.) were then orally administered to respective groups of rats $(n=6)$. Thirty minutes later, glucose (3 $g$ $\mathrm{kg}^{-1}$ ) was orally administered to each rat with a feeding syringe (Al-Awadi et al., 1985). Blood samples were collected from the tail vein by tail milking at $-30 \mathrm{~min}$ (just before the administration of extract and glibenclamide), 0 (just before the oral administration of glucose), 60, 120 and $180 \mathrm{~min}$. after glucose load. Blood glucose level was determined by One-Touch ${ }^{\circledR}$ glucometer. OGTT was performed in STZ-diabetic and normal rats using the same procedure.

\subsection{Estimation of Glycosylated Hemoglobin}

Rats were divided into six groups and treated as described above but for 8 weeks. Glycosylated hemoglobin was determined by assay kit (Excel Diagnostics Pvt. Ltd. India) based on ion exchange method (Nathan et al., 1984). Briefly, whole blood was mixed with lysing agent for the preparation of hemolysate. Elimination of Schiff's base was achieved during hemolysis. The hemolysed preparation was mixed continuously for five minutes with a weak binding cation-exchange resin. During this time, nonglycosylated hemoglobin binds to the resin leaving glycosylated hemoglobin (HbAlc) free in the supernatant. After the mixing period, a filter was used to separate the supernatant containing the glycosylated hemoglobin from the resin. The glycosylated hemoglobin was determined by measuring the absorbance of the glycosylated hemoglobin fraction and the total hemoglobin fraction at $415 \mathrm{~nm}$. The ratio of the two absorbances gives the percentage of glycosylated hemoglobin. 


\subsection{Preparation of Tissue Homogenates}

After 28-day treatment with the plant extract (NLet), the rats were sacrificed and blood samples were collected into heparinized tubes. Segments of the liver, kidney and pancreas tissues were excised separately from rats in all the experimental groups. The tissues were washed with phosphate buffered saline (pH 7.4) containing $0.16 \mathrm{mg} \mathrm{mL}^{-1}$ of heparin to remove any red blood cells (erythrocytes) and clots (Prasad et al., 1992). The tissues were then homogenized with an ultrasonic homogenizer in cold phosphate buffer, $\mathrm{pH} 7.0$ with Ethylenediaminetetra Acetic Acid (EDTA), for malondialdyhyde (MDA) measurement. The tissue homogenates obtained were centrifuged at $3,000 \mathrm{~g}$ for $10 \mathrm{~min}$ at $4^{\circ} \mathrm{C}$ and the supernatant was used for the assay.

\subsection{Estimation of MDA Concentration}

The product of the reaction between MDA and Thiobarbituric Acid Reactive Substances (TBARS) was estimated by a modified method of Ohkawa et al., (1979). A volume of $250 \mu \mathrm{L}$ of liver, kidney or pancreas homogenate was mixed with $100 \mu \mathrm{L}$ of $8.1 \%$ Sodium Dodecyl Sulfate (SDS), $750 \mu \mathrm{L}$ of $20 \%$ acetic acid and $750 \mu \mathrm{L}$ of $0.8 \%$ aqueous solution of Thiobar Bituric Acid (TBA) were added. The volume was made up to $4 \mathrm{ml}$ with distilled water, mixed thoroughly and incubated in boiling water for $45 \mathrm{~min}$. After cooling, 4 $\mathrm{ml}$ of n-butanol was added to each tube and the contents were mixed thoroughly. It was thereafter centrifuged at $3000 \mathrm{rpm}$ for 10 minutes. The absorbance of the clear, upper (n-butanol) layer was measured using Shimadzu (Japan) UV-1601 spectrophotometer at $532 \mathrm{~nm}$. Protein concentration was determined by Lowry et al. (1951) method.

The MDA concentration was calculated using the extinction coefficient of MDA-TBA complex $\left(1.56 \times 10^{5}\right.$ $\mathrm{cm}^{-1} \mathrm{M}^{-1}$ ) and was expressed as nmol MDA/mg protein.

\subsection{Statistical Analysis}

Data obtained from the experiments were expressed as mean \pm Standard Error of Mean (SEM). For statistical analysis, data were subjected to oneway Analysis of Variance (ANOVA) followed by Student's t-test. A level of $\mathrm{p}<0.05$ was considered significant. GraphPad Prism version 5.0 for windows was used for these statistical analyses (GraphPad software, San Diego California USA).

\section{RESULTS}

\subsection{Effect of NLet on Fasting Blood Glucose}

The hypoglycemic effect of repeated oral administration of $N$. laevis ethanolic extract in diabetic rats is shown in Table $\mathbf{1}$.

Before treatment schedule, fasting blood glucose was within the normal level in all the animals. Following induction of diabetes with STZ, there was a sharp increase in the average value of fasting blood glucose. After four weeks of treatment with NLet and glibenclamide, fasting blood glucose of streptozotocininduced diabetic rats significantly $(\mathrm{p}<0.05)$ decreased in a dose-dependent manner.

\subsection{Effect of NLet on Glycosylation of Hemoglobin}

The changes in the percentage of the total hemoglobin glycated in both test and control groups are presented in Fig. 1. Following the 8-week treatment of diabetic rats with the ethanolic extract of the leaves of Newbouldia laevis, the rate of glycosylation of hemoglobin was significantly $(\mathrm{p}<0.05)$ reduced in a dose-dependent manner.

\subsection{Effect of NLet on Oral Glucose Tolerance Test}

After oral glucose load, the blood glucose level of untreated non-diabetic rats (normal control) reached a peak at $60 \mathrm{~min}$ and gradually decreased to pre-glucose load level. NLet $\left(500 \mathrm{mg} \mathrm{kg}^{-1}\right)$ caused a significant attenuation in blood glucose level at $120 \min (p<0.05)$ and $180 \mathrm{~min}(\mathrm{p}<0.01)$ compared to the control (Fig. 2). In diabetic rats, NLet also caused significant decrease in blood glucose at $120 \mathrm{~min}(\mathrm{p}<0.05)$ and $180 \min (\mathrm{p}<0.01)$ compared to the diabetic control. In both normal and diabetic rats, glibenclamide $\left(5 \mathrm{mg} \mathrm{kg}{ }^{-1}\right)$ produced significant reduction in blood glucose level at 60,120 and $180 \mathrm{~min}(\mathrm{p}<0.01)$ compared with diabetic control (Fig. 3).

\subsection{Effect of NLet on Lipid Peroxidation}

In the liver, kidney and pancreas, MDA concentration in the diabetic control rats was significantly higher $(p<0.05)$ compared to those obtained in the normal control and the treated groups. It was observed that lipid peroxidation was less in liver compared to pancreas and kidney. The MDA concentration of diabetic animals was dose-dependently reduced by the extract. At 300 and $500 \mathrm{mg} \mathrm{kg}{ }^{-1}$, the reduction was significant $(\mathrm{p}<0.05)$ and was comparable to that observed with glibenclamide (Fig. 4). 


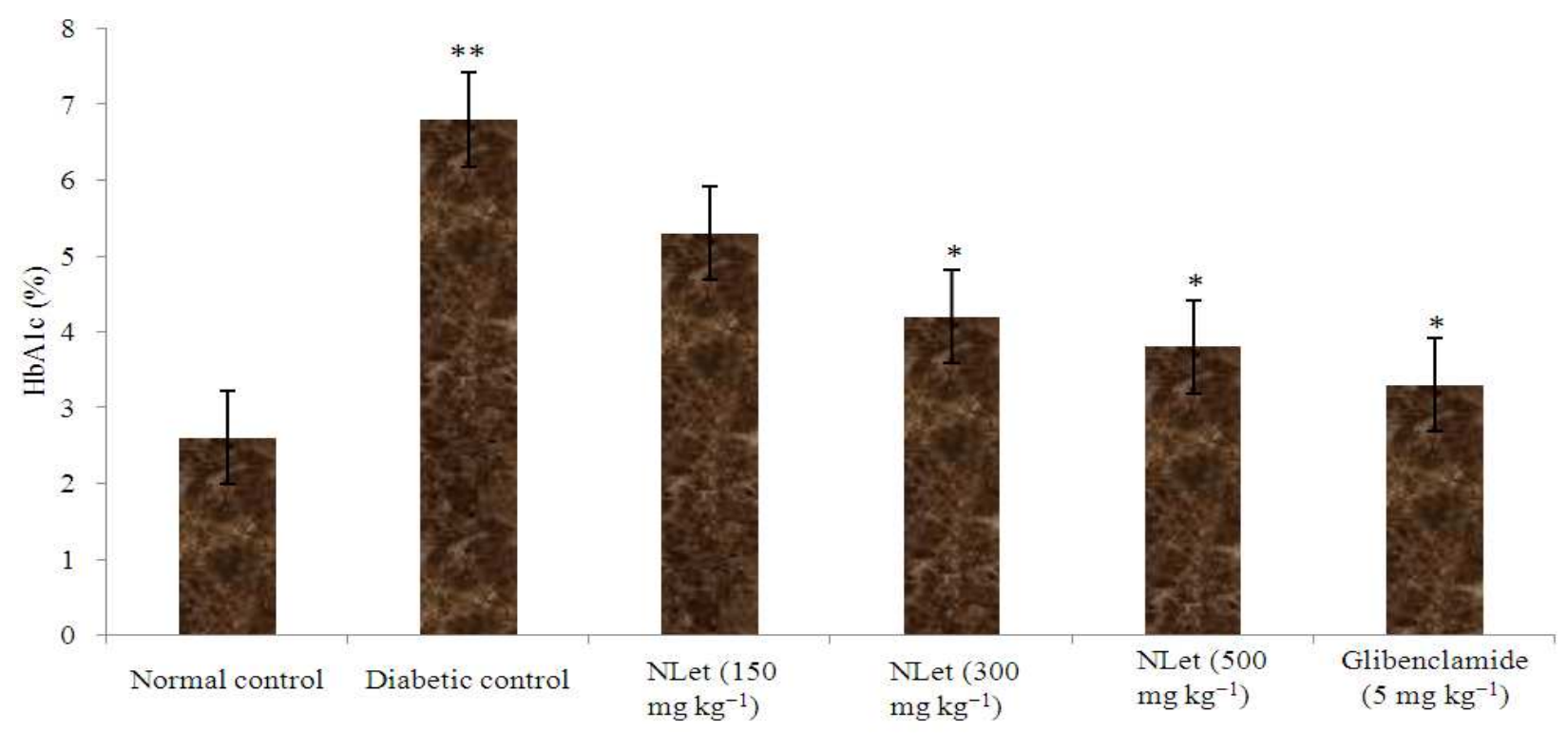

Fig. 1. Effect of $N$. laevis leaf extract on glycosylation of hemoglobin in diabetic rats. Values represent mean \pm SEM $(\mathrm{n}=6)$. ${ }^{* *} \mathrm{p}<0.05$ compared with normal control; ${ }^{*} \mathrm{p}<0.05$ compared with diabetic control

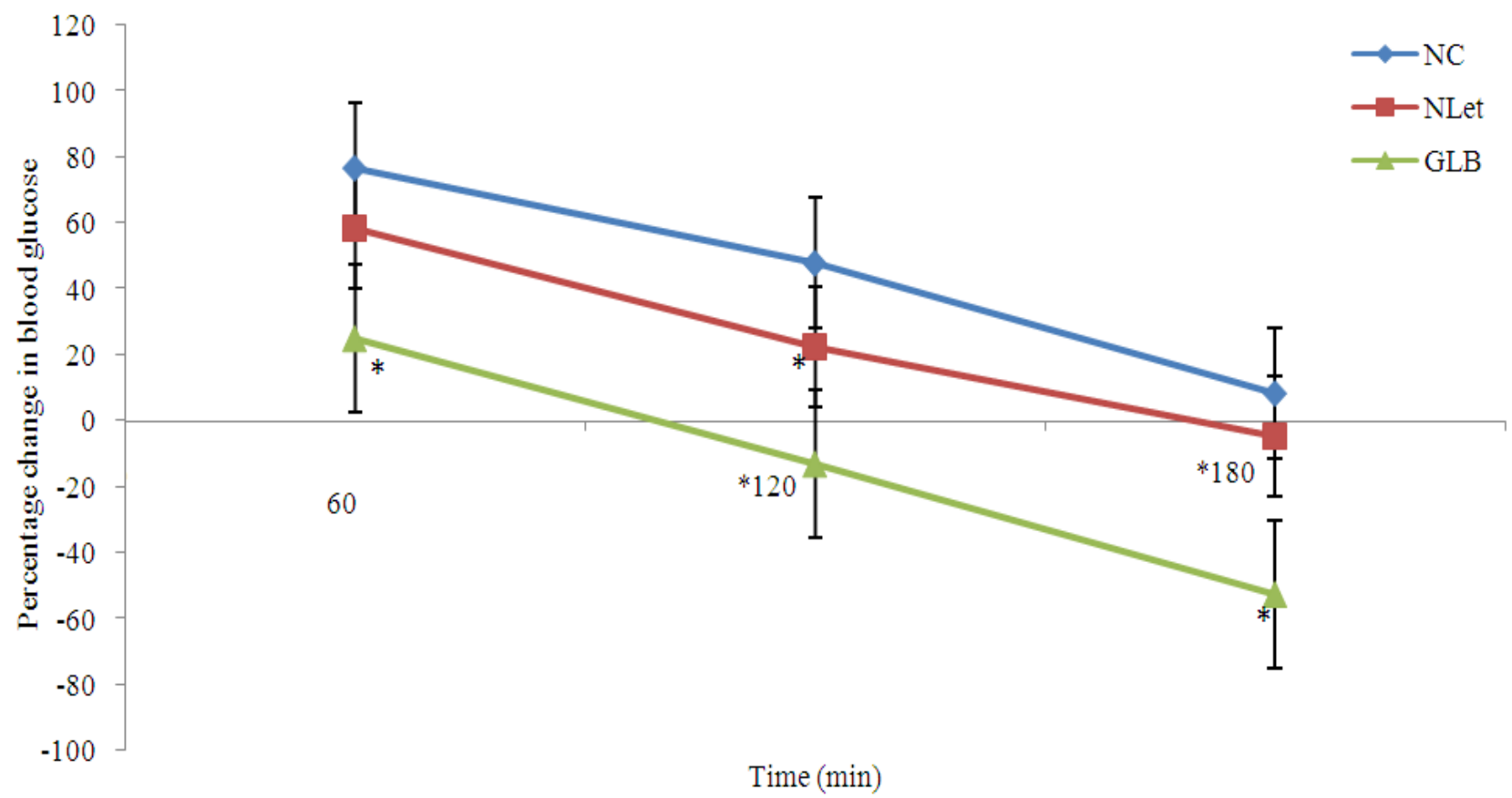

Fig. 2. Oral glucose tolerance test in normal rats. values are expressed as the mean \pm SEM for 6 rats in each group. The $\%$ change in blood glucose at 60,120 and $180 \mathrm{~min}$ was calculated from the corresponding 0 min value (just before the oral administration of glucose) in each group. ${ }^{*} \mathrm{p}<0.05$ compared with control. $\mathrm{NC}=$ normal control; GLB $=$ glibenclamide; NLet $=$ ethanolic extract of $N$. laevis 
Kolawole O. Timothy et al. / American Journal of Pharmacology and Toxicology 8 (4): 179-186, 2013

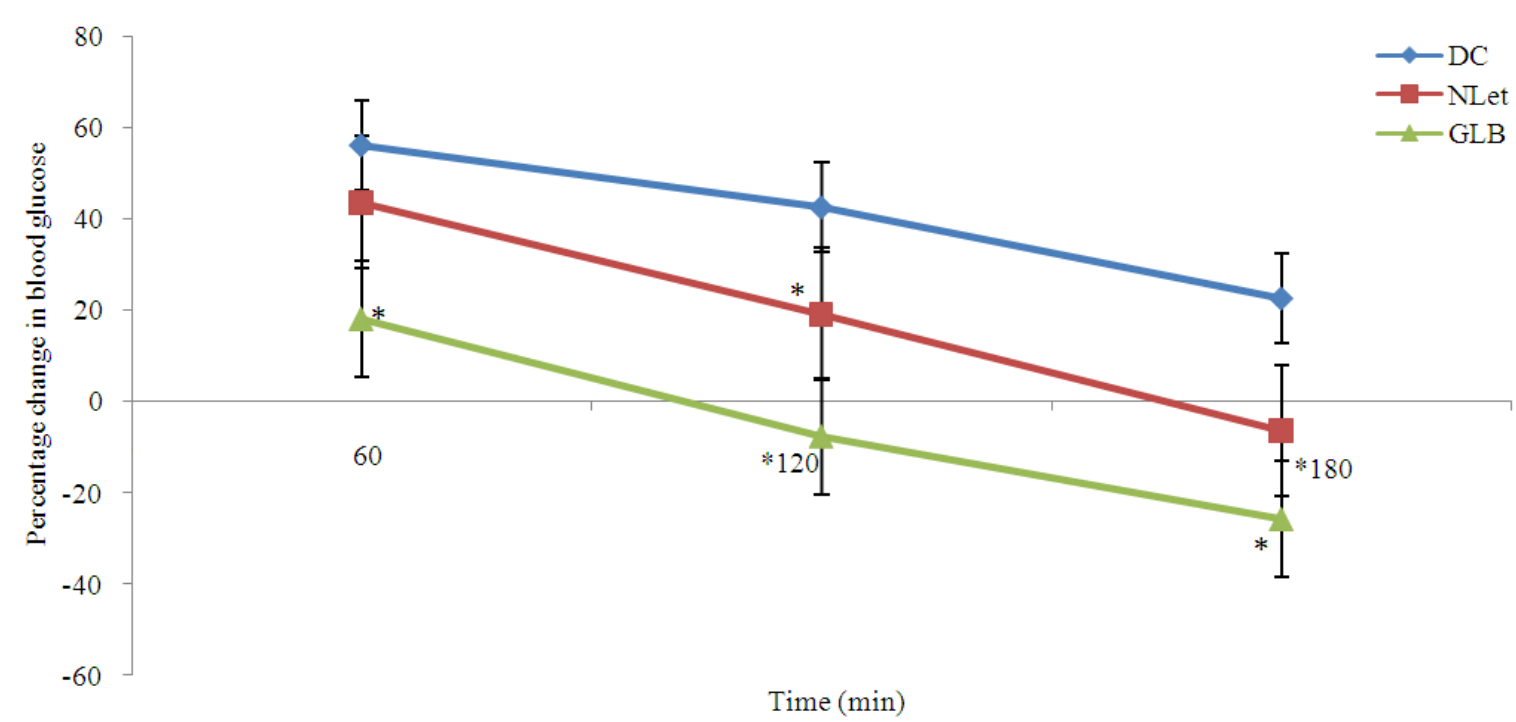

Fig. 3. Oral glucose tolerance test in diabetic rats. Values are expressed as the mean \pm SEM for 6 rats in each group. The \% change in blood glucose at 60,120 and $180 \mathrm{~min}$ was calculated from the corresponding 0 min value (just before the oral administration of glucose) in each group. ${ }^{*} \mathrm{p}<0.05$ compared with control. $\mathrm{DC}=$ diabetic control; GLB $=$ glibenclamide; $\mathrm{NLet}=$ ethanolic extract of $N$. laevis

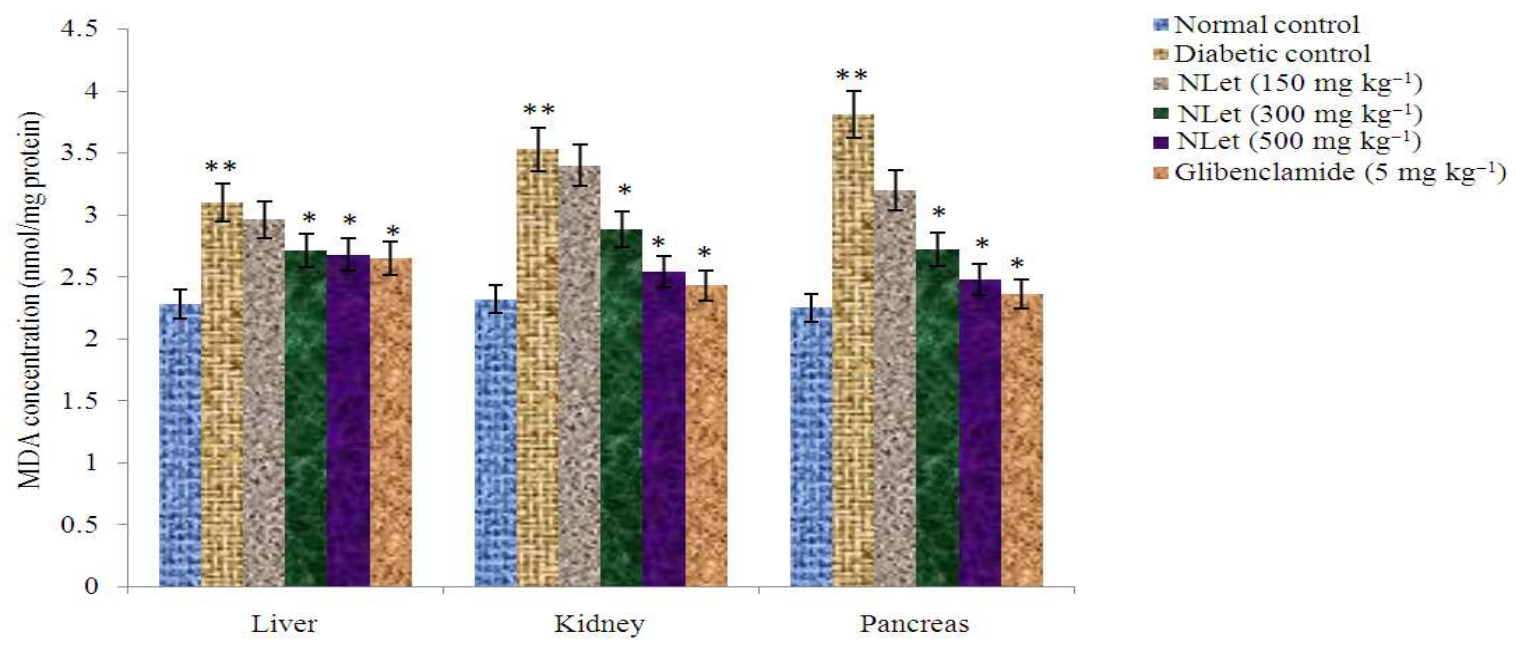

Fig. 4. Effect of $N$. laevis extract on lipid peroxidation in the liver, kidney and pancreas of diabetic rats. Values are mean $\pm \mathrm{SEM}(\mathrm{n}=$ 6). ${ }^{*} \mathrm{p}<0.05$ compared to diabetic control; ${ }^{* *} \mathrm{p}<0.05$ compared to normal control

Table 1. Effect of Newbouldia laevis leaf extract on fasting blood glucose in diabetic rats Fasting blood glucose (mg/dl)

\begin{tabular}{|c|c|c|c|}
\hline & Day 0 & Day 29 & Day 15 \\
\hline Normal control & $96.80 \pm 4.24$ & $95.91 \pm 5.03^{\mathrm{a}}(-0.93)$ & $97.28 \pm 5.96^{\mathrm{a}}(+0.41)$ \\
\hline Diabetic control & $262.55 \pm 8.83$ & $283.68 \pm 7.66^{\mathrm{b}}(+8.00)$ & $298.40 \pm 9.22^{b}(+13.73)$ \\
\hline NLet $\left(150 \mathrm{mg} \mathrm{kg}^{-1}\right)$ & $277.81 \pm 6.46$ & $241.42 \pm 5.21^{\mathrm{c}}(-13.09)$ & $219.38 \pm 8.50^{\mathrm{c}}(-21.03)$ \\
\hline NLet $\left(300 \mathrm{mg} \mathrm{kg}^{-1}\right)$ & $286.60 \pm 10.13$ & $196.33 \pm 8.92^{\mathrm{c}}(-31.47)$ & $181.00 \pm 7.32^{\mathrm{c}}(-36.60)$ \\
\hline NLet $\left(500 \mathrm{mg} \mathrm{kg}^{-1}\right)$ & $280.55 \pm 9.92$ & $178.60 \pm 7.02^{b}(-36.34)$ & $112.13 \pm 6.60^{b}(-60.03)$ \\
\hline Glibenclamide $\left(5 \mathrm{mg} \mathrm{kg}^{-1}\right)$ & $275.68 \pm 10.66$ & $166.74 \pm 8.46^{\mathrm{c}}(-39.50)$ & $100.95 \pm 5.39^{\mathrm{c}}(-63.41)$ \\
\hline
\end{tabular}

Values represent mean \pm SEM $(n=6)$. Values in bracket are percentage change in blood glucose from Day 0 . Means with different superscript within columns are significantly different $(\mathrm{p}<0.05)$ 


\section{DISCUSSION}

Globally, diabetes has become one of the leading causes of death. It is a disease that destroys the very engine of life. Therefore, more treatment options are needed to reduce the socio-economic impact and prevent the complications of diabetes. In poorly controlled diabetes, there is upsurge in the glycosylation of some proteins including hemoglobin. With time, glycosylated hemoglobin develops reduced affinity for oxygen which contributes to long-term complications of diabetes (Latha and Pari, 2004). Glycosylated hemoglobin is an excellent marker of glycemic control because it is formed irreversibly and is stable over the life span of the red blood cells (Daisy and Rajathi, 2009).

In this study, experimental diabetes was induced in rats by Streptozotocin (STZ). STZ-induced diabetes is a well-established animal model of diabetes mellitus. In STZ-induced animal models of diabetes, insulin is markedly depleted but not absent (Frode and Medeiros, 2008). Glycosylated hemoglobin level was elevated in diabetic rats.

The significant decrease in the level of glycosylated hemoglobin in STZ-diabetic rats following treatment with NLet is an indication that the overall blood glucose level was controlled. The results of fasting blood glucose and oral glucose tolerance tests which agree with the report of Owolabi et al. (2011) also confirm the antidiabetic potentials of the extract. Some other medicinal plants have also been reported to have the ability to reduce glycosylated hemoglobin levels in diabetic rats (Venkateswaran and Pari, 2002).

Increased MDA concentration is an important indicator of lipid peroxidation (Ambali et al., 2011). MDA concentration in the diabetic control rats was significantly higher $(\mathrm{p}<0.05)$ compared to those obtained in the normal control and the treated groups. It was observed that lipid peroxidation was less in the liver compared to pancreas and kidney. This agrees with the observation of Oberley (1988) and Tatsuki et al. (1997) that the liver has higher capacity to cope with oxidative stress than other organs.

The role of biological membranes is very important for the survival of the cell. They serve as selectively impermeable barrier and are involved in cellular transport processes. Through the process of lipid peroxidation, the homeostasis and function of cell membrane are impaired leading to cellular dysfunction and damage (Dargel, 1992). Reactive Oxygen Species (ROS) such as hydroxyl radical and protonated form of superoxide anion commonly initiate the process of autocatalytic lipid peroxidation. This eventually results in the conversion of unsaturated lipids into polar lipid hydroperoxides. The net effects are increased membrane fluidity, efflux of cytosolic solutes and loss of membrane integrity (Avery, 2011). NLet significantly reduced lipid peroxidation in a dosedependent manner. The ability of NLet to suppress lipid peroxidation and glycation of hemoglobin in diabetic rats indicates that it can prevent cell injury and complications such as atherosclerosis and kidney damage.

\section{CONCLUSION}

The results of this study indicate that ethanolic extract of the leaves of Newbouldia laevis possesses antidiabetic properties. It can prevent the complications of diabetes that result from glycation of hemoglobin and lipid peroxidation. Further studies should be carried out on this plant in order to understand its mechanism of action.

\section{REFERENCES}

Al-awadi, F.M., M.A. Khattar and K.A. Gumaa, 1985. On the mechanism of the hypoglycaemic effect of a plant extract. Diabetologia, 28: 432-434. DOI: 10.1007/BF00280886

Alberti, K.G. and P.Z. Zimmet, 1998. Definition, diagnosis and classification of diabetes mellitus and its complications. Part 1: diagnosis and classification of diabetes mellitus provisional report of a WHO consultation. Diabet Med., 15: 539-553. PMID: 9686693

Ambali, S.F., J.O. Ayo, K.A. Esievo and S.A. Ojo, 2011. Hemotoxicity induced by chronic chlorpyrifos exposure in wistar rats: Mitigating effect of vitamin C. Vet. Med. Int., 2011: 945439. DOI: 10.4061/2011/945439

Avery, S.V., 2011. Molecular targets of oxidative stress. Biochem. J., 434: 201-210. DOI: 10.1042/BJ20101695

Chen, H., S. Brahmbhatt, A. Gupta and A.C. Sharma, 2005. Duration of streptozotocin-induced diabetes differentially affects p38-Mitogen-Activated Protein Kinase (MAPK) phosphorylation in renal and vascular dysfunction. Cardiovascular Diabetol. DOI: 10.1186/1475-2840-4-3

Daisy, P. and M. Rajathi, 2009. Hypoglycemic effects of clitoria ternatea linn. (Fabaceae) in Alloxaninduced diabetes in rats. Trop. J. Pharml. Res., 8: 393-398. 
Dargel, R., 1992. Lipid peroxidation-a common pathogenetic mechanism? Exp. Toxicol. Pathol., 44: 169-181. DOI: 10.1016/S0940-2993(11)80202-2

Elujoba, A.A., O.M. Odeleye and C.M. Ogunyemi, 2005. Traditional medicine development for medical and dental primary health care delivery system in Africa. Afr. J. Trad. CAM., 2: 46-61.

Frode, T.S. and Y.S. Medeiros, 2008. Animal models to test drugs with potential antidiabetic activity. J. Ethnopharmacol., 115: 173-183. DOI: 10.1016/j.jep.2007.10.038

Giugliano, D., A. Ceriollo and G. Paolisso, 1996. Oxidative stress and diabetic vascular complications. Diabetes Care, 19: 257-267. PMID: 8742574

IEC, 2009. International expert committee report on the role of the a1c assay in the diagnosis of diabetes. Diabetes Care, 32: 1327-1334. DOI: $10.2337 / \mathrm{dc09}-$ 9033

Kuete, V., K.O. Eyong, G.N. Folefoc, V.P. Beng and H. Hussain et al., 2007. Antimicrobial activity of the methanolic extract and of the chemical constituents isolated from Newbouldia laevis. Pharmazie, 62: 552-556. PMID: 17718200

Latha, M. and L. Pari, 2004. Effect of an aqueous extract of Scoparia dulcis on blood glucose, plasma insulin and some polyol pathway enzymes in experimental rat diabetes. Braz. J. Med. Biol. Res., 37: 577-586. PMID: 15064821

Lowry, O.H., N.J. Rosebrough, A.L. Farr and R.J. Randall, 1951. Protein measurement with the folin phenol reagent. J. Biol. Chem., 193: 265-275.

Nathan, D.M., D.E. Singer, K. Hurxthal and J.D. Goodson, 1984. The clinical information value of the glycosylated hemoglobin assay. N. Engl. J. Med., 310: 341-346. PMID: 6690962

NIH, 1985. Principles of Laboratory Animal Care. NIH Publication No. 85-23 revised.

Oberley, L.W., 1988. Free radicals and diabetes. Free Radic. Biol. Med., 5: 113-124. PMID: 3075947
Ogunlana, O.E. and O.O. Ogunlana, 2008. In vitro assessment of antioxidant activity of Newbouldia laevis. J. Med. Plants Res., 2: 176-179.

Ohkawa, H., N. Ohishi and K. Yagi, 1979. Assay for lipid peroxides in animal tissues by thiobarbituric acid reaction. Anal. Biochem., 95: 351-358. DOI: 10.1016/0003-2697(79)90738-3

Owolabi, O.J., F.C. Amaechina and M. Okoro, 2011. Effect of ethanol leaf extract of Newbouldia laevis on blood glucose levels of diabetic rats. Trop. J. Pharmaceutical Res., 10: 249-254.

Prasad, K., P. Leep, S.V. Mantha, J. Kalra and M. Prasad et al., 1992. Detection of ischemia-reperfusion cardiac injury by cardiac muscle chemiluminescence. Mol. Cell Biochem., 115: 4958. PMID: 1435765

Syed, I.A., 2011. Glycated hemoglobin; past, present and future are we ready for the change. J. Pak. Med. Assoc., 61: 383-388. PMID: 21465979

Tatsuki, R., K. Satoh, A. Yamamoto, K. Hoshi and K. Ichihara, 1997. Lipid peroxidation in the pancreas and other organs in streptozotocin diabetic rats. Jpn. J. Pharmacol., 75: 267-273. PMID: 9434258

Trinder, P., 1969. Determination of blood glucose using an oxidase-peroxidase system with a noncarcinogenic chromogen. J. Clin. Pathol., 22: 158161. PMID: 5776547

Venkateswaran, S. and L. Pari, 2002. Antioxidant effect of Phaseolus vulgaris in streptozotocin-induced diabetic rats. Asia Pacific J. Clin. Nutr., 11: 206209. PMID: 12230234

Yan, S.F., V. D’Agati, A.M. Schmidt and R. Ramasamy, 2007. Receptor for Advance Glycation Endproducts (RAGE): A formidable force in the pathogenesis of the cardiovascular complications of diabetes and aging. Curr. Mol. Med., 8: 699-710. PMID: 18331228 